\title{
Conceptualising Trust in E-Participation Contexts
}

\author{
Sabrina Scherer and Maria A. Wimmer \\ University of Koblenz-Landau, Germany \\ \{scherer, wimmer\}@uni-koblenz.de
}

\begin{abstract}
Citizen engagement in political discourse and in democratic decisionmaking via innovative online means (coined e-participation) has become subject of considerable research over the past decade. However, mass engagement of citizens in online consultation and decision-making contexts remains an unsatisfied expectation. In this paper, we investigate trust as a particular aspect that might influence whether a citizen will participate. Trust is perceived as a complex construct, which is subject of research in distinct research disciplines. To identify and implement measures for increasing trust as well as for minimising distrust in e-participation endeavours, relevant trust relationships have to be analysed to understand implications of using or not using e-participation offers. In this paper, the status of current research of trust in citizen participation supported by electronic means is investigated. The literature review unveils that various implications of trust in the context of e-participation are still not researched well. Existing studies investigate particular aspects of trust. Yet, no conceptualisation of a trust model is available that explains the full scope of trust in e-participation contexts. Hence this paper puts forward such a trust model for e-participation, which builds on the Integrative Model of Trust in Organisational Settings by Mayer, Davis and Schoorman (1995) and the Interdisciplinary Model of Trust Constructs by McKnight and Chervany (2001).
\end{abstract}

Keywords: e-participation, participation, trust, trust model.

\section{Introduction}

Several studies have unveiled the importance of trust in e-participation (see e.g. [1-6]). Resulting from the interdisciplinary nature of e-participation [7, p.415], no clear overview of theories and methods applied as well as results achieved so far exist. The complexity of understanding and describing trust in distinct research disciplines [8-12] makes it even more difficult "to follow and [...] to compare [results in trust research] with each other" [12, p.28]. To overcome these challenges, the usefulness of a conceptualisation of trust to form a comprehensive understanding is e.g. argued in [12, p.29, 13, p.974ff, 14, p.36].

This work, being motivated by a research grant by the State Rhineland-Palatinate ${ }^{1}$, aims at building a theoretical model for scoping trust in e-participation contexts with

\footnotetext{
${ }^{1}$ The research grant "Communication, Media and Politics" (KoMePol) investigates, among other aspects, trust in mediation, perception and processing of politically relevant discourses. The project is divided into distinct sub-projects, where " $m$ Part - mobile participation of citizens with privacy protection" focuses on the role of trust in e-participation. More information is available at https : / / www . uni-koblenz-landau. de/komepol / (access 2014-05-28).
} 
the purpose of investigating the various phenomena of trust from distinct perspectives. The ultimate goal is to derive a trust model for e-participation and to identify the various trust factors in this context. Such a model will help to systematise existing and future studies of trust in e-participation contexts to enable better comparability and better identification of interdependencies of study results and the methods applied thereby from distinct disciplines. This model, together with the systematisation and comparative analysis of existing studies, paves the way for a better understanding of the importance of factors that influence trust in e-participation, which in turn can also inform the design and implementation of e-participation initiatives.

The remainder of the paper is as follows: Section 2 reviews literature to provide the foundations of our research. In section 3, two trust models are exemplified to demonstrate how far they can provide a foundation for a conceptualisation of trust in e-participation. The analysis also shows, which characteristics of e-participation are not represented with these models, and where the trust models need to be extended or adapted for e-participation contexts. As no comprehensive conceptualisation of trust in e-participation could be identified, a trust model for e-participation is proposed in section 4. The model is derived from the findings of exemplifying existing trust models for e-participation. We conclude by arguing the applicability of the proposed model to scope trust in e-participation contexts and by identifying research needs.

\section{Literature Review}

\subsection{Trust Definitions and Existing Trust Models}

Due to the complexity of trust as an 'interpersonal and organisational' [8, p.3] as well as multidimensional construct [13, p.976], various attempts of defining [8-13, 15-18] and modelling [11-13, 15, 19] trust exist - both originating from diverse disciplines as e. $\mathrm{g}$. sociology, psychology, political science, economics [15, p.138]. Not only between, but also within the diverse disciplines, no congruent definition of trust exists [12, p.31]. Luhmann criticises that the notion of trust would be often used incorrectly, carrying in his criticism, for example, reference to "the research on trust or distrust in politics" [9, p.143]. Following Luhmann, 'issues of trust' might be confused with positive or negative attitudes towards the political leadership or the political institutions, with alienation, with hopes and fears, or with confidence [9, p.143]. The need of one party to trust is defined as a result of some vulnerability to another party; and making oneself vulnerable would mean to take a risk [11, p.712]. Hence, Mayer et al. see trust as " $a$ willingness to take risk" [11, p.712] or a solution for specific risk challenges [9, p.144] in difference to other terms as 'cooperation', 'confidence' and 'predictability' by their definition [12, p.712ff]. Another way of explaining the meaning of trust is by using models to conceptualise the scope of trust [12, p.28]. In this regard, two trust models are presented in this section: (1) Integrative Model of Trust in Organisational Settings [11] by Mayer, Davis and Schoorman (1995) and (2) the Interdisciplinary Model of Trust Constructs [12] by McKnight and Chervany (2001). Mayer et al.'s model has been selected as a prominent trust model often cited in different areas as e.g. marketing, finance, economics, information systems, political 
science, communication, ethics, law, psychology, sociology while stemming itself from management and general business [20, p.334]. McKnight's and Chervanny's model is often cited in literature ${ }^{2}$, too. Already an earlier version of this model has been applied to study trust in organisations, in e-commerce and in virtual teams [21, p.32]. It has been selected here as it proposes some elements that complement Mayer et al.'s model as we will argue further on, and it has been applied in another e-discipline [14].

Mayer et al.'s trust model focuses on "trust in an organisational setting" [11, p.711]. The model presents trust as "an aspect of relationships" that "varies within persons and across relationships" [20, p.344]. The model involves "a trusting party (trustor) and a party to be trusted (trustee)" [11, p.711], and it introduces dynamic trust relationships between both parties. Trust is explicitly differentiated from the activity as a result from risk (i.e. Risk taking in relationship - RTR). The decision to take this relationship depends on a function comparing the level of trust to the level of perceived risk in a situation [11, p.726]. The outcome of a risk taking relationship influences factors of perceived trustworthiness (ability, benevolence, integrity) in the next feedback loop - i.e. entering the trust relationship again. Mayer et al.'s model of trust in an organisational setting is visualised in Fig. 1. For details, the reader is referred to $[11,20]$.

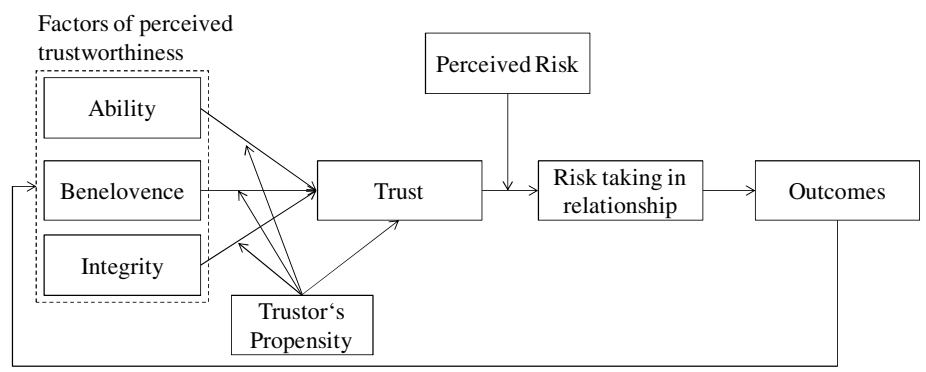

Fig. 1. Mayer et al.'s integrative model of trust in organisational settings [11, p.715]

The complexity of the examined relationships of trust in e-participation makes it necessary to consider the term 'trust' not only from "interpersonal, intergroup, or interorganisational levels of analysis" as it is done in the Mayer et al. model [20, p.345]. Trust in "big ideas, programs, parties, political systems, social changes" as suggested in [17, p.11] is another aspect to be understood. McKnight \& Chervany introduce different perspectives in their 'interdisciplinary model of trust constructs' [12, p.31ff], which are: (a) a dispositional perspective regarding trust in general / trust in others, (b) an institutional perspective regarding trust in the situation or structures, and (c) an interpersonal perspective regarding trust in specific others. Five trust types are classified in these perspectives as visualised in Fig. 2: Disposition to trust means the general willingness of trustor to depend on general others [12, p.38].

${ }^{2}$ Following Google Scholar, the article has been cited more than 200 times (http: / /scholar.google.de/scholar?cites=904032774768167641\&as_s $d t=2005 \&$ sciodt $=0,5 \& h l=d e$, access 2014-05-20) 
Institution-based trust means that one believes that favourable conditions exist, which are conducive to situational success in a risky aspect of life [12, p.37]. Trusting beliefs describe "cognitive perceptions about the attributes or characteristics of the trustee" [12, p.36]. Trusting intentions means the willingness of trustor to depend on particular others [12, p.34] i.e. the trustee. Trust-related behaviour describes the act that trustor is depending in a situation [12, p.34]. The arrows indicate how these types of trust influence each other. McKnight and Chervany state that these types of trust are supported consistently by empirical data [12, p.40].

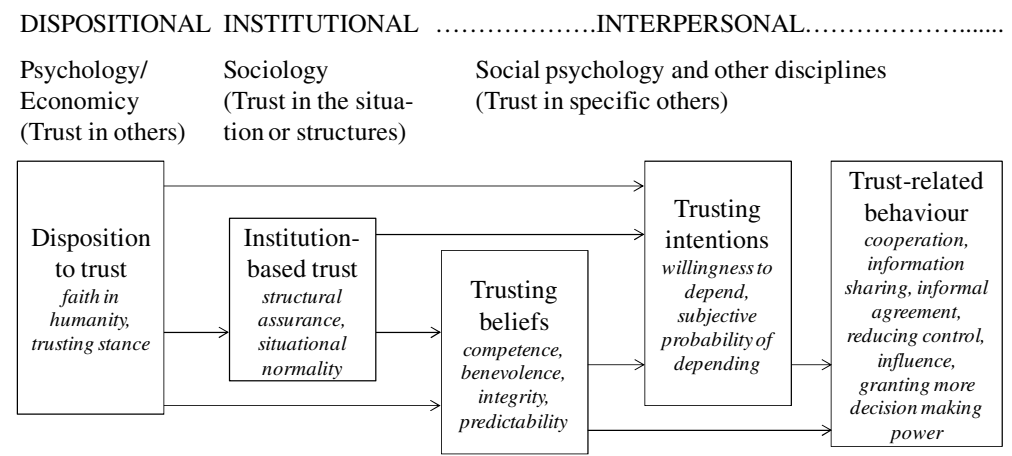

Fig. 2. Interdisciplinary model of trust constructs [12, p.33]

Distrust is differentiated from trust by defining it as separate and opposite from trust [12, p.41ff]. For details the reader is referred to [12, 14, 22].

As McKnight \& Chervany's model is influenced by Mayer et al.'s model, similarities are recognisable, for example: (i) Both models refer to trust in general and "not in a specific situation", so the other party is "the object of trust" [12, p.34]. Researchers who decompose "trust constructs into particular trust-related situation segments would obtain indicators of the overall relationship between trustor and trustee" [12, p.34]. (ii) 'Trust-related behaviour' in McKnight \& Chervany's model "implies acceptance of risk" and corresponds to the "risk taking in relationship" in Mayer et al.'s model [12, p.35]. (iii) McKnight \& Chervany express that the "trustor behaviourally depends on a trustee". This gives the trustee "some measure of power over the trustor" [12, p.35]. (iv) 'Trusting beliefs' correspond with factors of trustworthiness in Mayer et al.'s model even though Mayer et al. add the factor 'predictability'. (v) 'Disposition to trust' conforms to some extent to 'trustor's propensity' in Mayer et al.'s model. (vi) 'Trusting intentions' can be compared with weighing up trust and perceived risk in Mayer et al.'s model. However, McKnight \& Chervany's model extends Mayer et al.'s model by adding more details to comparable elements, by differentiating between 'disposition to trust' and 'trusting intentions' - adding an element to consider institution-based trust - and by not putting the risk as the focal point of the model. The Mayer et al. model looks into dynamics of trust by considering outcomes of a trust-related behaviour and how these influence other trust types. The McKnight \& Chervany model lacks such a dynamic view.

To complement these understandings, next subsection reviews definitions and trust models as emerging in e-government research. 


\subsection{Trust Definitions and Models in e-Government Research}

In e-government research, definitions that base on the perception that some party 'is exploited' by another party are criticised e.g. by Bannister and Connolly with the argument that distrust in government would "not necessarily express a concern about personal risk" [15, p.139]. Such understanding would rather express a judgement of the government's competence [15, p.139]. Risks could "range from government imposing additional taxes to State abuse of power, for example by arbitrary arrest and detention" [15, p.140]. The UN study of trust in e-government uses the following definition: "trust occurs when parties holding certain favourable perceptions of each other allow this relationship to reach the expected outcomes" (citing Wheeless and Grotz 1977) in [8, p.251]). However, other scholars see perceived risk as necessary construct in any research model of trust in e-government [23, p.95].

A model differentiating types of trust relevant in e-government is described by Blind [8]. This model differentiates between political, social, technological, moral, and economic trust as well as trust in government. Another synthesis of trust objects, i.e. the objects towards which trust is directed in a situational context is conducted by Papadopoulou et al. [19]. The forms of trust defined there reflect a more detailed differentiation of the model proposed by Blind in regards to technological trust, as trust objects by Papadopoulou et al. are categorised into the following types of trust [19, p.10ff]: trust in stored data, service, information, system, transaction, government organisation, and institution-based trust.

In Korea, a study analysing the implications of Internet usage on trust in government reveals a negative relation of Internet usage in general towards trust in government [3]. The authors argue further that the use of e-government could "reduce the negative impact of the Internet on trust in government" [3, p.16]. It is to be tested, whether this also applies to e-participation.

Next subsection provides insights into the status of research on trust in e-participation.

\subsection{Trust in e-Participation Research}

Current research in trust and (e-)participation consists mainly of studies concentrating on particular aspects, e.g. trust in government or considering the use of electronic tools for political participation. Literature can be separated among researching trust in participation and trust in e-participation.

Trust in Participation. Uslaner \& Brown differentiate e.g. the objectives of people for taking part in their communities by types of participation (volunteering, giving to charity, voting, signing petitions, and working for a political party) [6]. The authors conclude that "trust plays an important role in participation levels, but contrary to more traditional models, the causal relationship runs from trust to participation" [6, p.868]. They further highlight the importance of the economic context for trust in participation. Grimmelikhuijsen \& Meijer investigate if and how far prior knowledge and predisposition to trust government influence the relation between transparency and trust [2, p.151]. No support for a general "positive effect of transparency on perceived 
trustworthiness" was found [2, p.151]: "In sum, "nä̈ve" trustees in government organisations lose their trust if government does not do a good job in creating transparency, whereas being naïve has an opposite effect when it comes to perceived benevolence" [2, p.154]. Another study investigates the hypothesis that public participation enhances public trust. It concludes that "participation affects [public] trust when it produces high-quality services that the public wants" and "enhanced ethical behaviour [integrity, honesty, and moral leadership] on the part of administration" [24, p.276]. Yet, consensus building alone as a result of participation "does not lead to public trust" [24, p.276]. Blind further observed implications of political participation and trust [8] as demonstrated through a relationship diagram in Fig. 3.

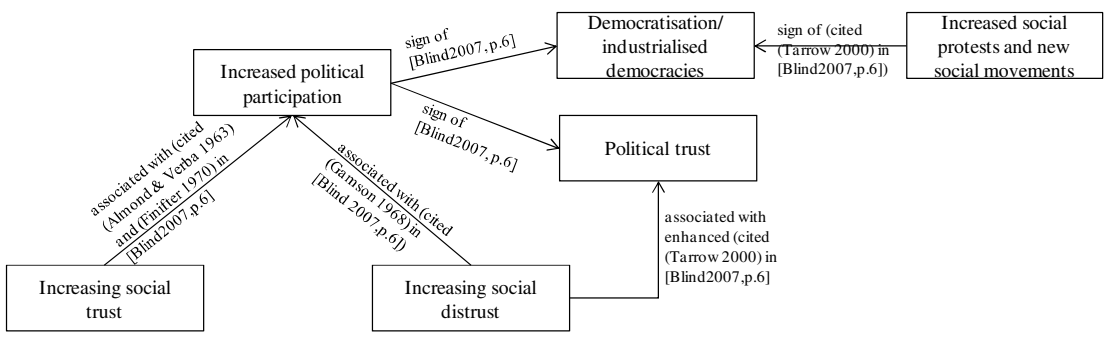

Fig. 3. Relationship diagram visualising dynamics of political participation and trust (derived from [8])

Trust in e-Participation. Kim \& Lee examine the relationship between e-participation and trust in local government. Instead of a simple and direct link between e-participation and public trust, the study investigates a structural model for analysing the influence of the e-participation process to citizens' development and empowerment, to government transparency and finally to public trust in government [4, p.826]. Following these causal links, the authors conclude that satisfaction of participants with the quality of government responsiveness and with the usefulness of the e-participation application has a positive influence on the assessment of government transparency and this increases the trust in the local government [4, p.824ff]. Veit et al. prove that trust in an e-participation tool influences positively the expected use and intended usage [25, p.1350]. Coleman \& Gotze highlight the importance of moderation and mediation and describe a number of rules for "trusted facilitation" of online engagement in policy deliberation [1, p.17f]. Findings by Lee \& Kim (2014) would suggest that "trust in government facilitates citizens to actively engage in citizeninitiated e-participation" [26, p.8]. Trust in government would encourage their "cooperation with government" and stimulate them to take over action.

The conclusion from studies is that the systematisation of the full scope and notion of trust in e-participation appears to be difficult. We therefore return to the trust models presented in section 2.1 and exemplify relevant aspects of these models for e-participation with the purpose to analyse their applicability and restrictions and, therewith, to identify amendments of these models to conceptualise trust in e-participation in a more comprehensive way. 


\section{Exemplifying e-Participation in Trust Models}

The context for exemplifying the models is defined as follows: The trustor is a person interested in taking part in an e-participation initiative. E-petitioning and participatory budgeting were selected for the exemplifications as these are famous and successful e-participation areas, where we gathered a deeper understanding through earlier research. The next two subsections expose the Mayer et al. and McKnight \& Chervany models to e-participation. Subsequently, we discuss and reflect the applicability of the models to the e-participation context and derive requirements for a revised model.

\subsection{Integrative Model of Trust in Organisational Settings}

The main Risk Taking Relationship (RTR) in our context of study is that the trustor (the participant) takes part in an e-participation initiative. Various individual relationships may be entered as activity of a participation process e.g. to comment, to take part in a poll, to sign a petition, etc. To analyse Perceived Risk, the motivation of the participant for participating needs to be considered (as context information). Here, the motivation is to change a legal/political situation because of personal interests of the participant. Possible direct Outcomes of the RTR are that e.g. a petition may have been refused or accepted. Indirect outcomes are for example satisfaction or dissatisfaction with the process, with the democratic system or the influence achieved, with the institutions and groups involved (e.g. government), with the contributions of others, with the ICT from an emotional point of view, etc. For negative outcomes, potential risks need to be identified. For the aforementioned negative outcomes, the following potential risks could be identified for participants (exemplification; further risks may exist):

- Legal/political situation does not change for the participant and therewith everything that the participant has invested (e.g. time) is lost without any benefit.

- User data may be utilised by other parties.

- Participant could experience personal disadvantages as a result of non-anonymous participation through different-minded parties.

If and how far these potential risks are perceived by individual participants depend on the persons themselves and the participation initiative (what impact is possible or expected). The decision to participate might not only base on risks identified. Further a type of calculation between possible positive outcomes (such a concept is not included in the Mayer model) and perceived risks (as condition for participation) might play a role. The relation in the trust model between outcomes and factors of trustworthiness is considering implications on trust as a result of participation. For Factors of Perceived Trustworthiness, involved responsible parties influencing the outcomes of the e-participation initiative could be considered as trustees. To all of them, Trust relationships may exist if the participant as trustor is aware of their involvement. Trustor's Propensity influences trust relationships. Trust in tools or channels is not considered. 


\subsection{Interdisciplinary Model of Trust Constructs}

Disposition to Trust is related to faith in humanity and trusting stance. It is relevant in e-participation to analyse trust in other participants or in the general public. Institution-based Trust, which is related to trust in systems and structures, and which differentiates between 'structural assurance' and 'situational normality', can consider trustor's propensity regarding different forms of trust as suggested by Blind [8]: political, social, technological, moral and economic trust (see section 2.1). Trust in Internet can e.g. be explained with the element 'institution-based trust' [14, p.43]. Table 1 exemplifies the roles of different perspectives used in the model for e-participation (based on an exemplification of the model for e-commerce [14, p.42]).

Table 1. Exemplifying the role of trust perspectives

\begin{tabular}{|l|l|}
\hline Participant trusts in ... & Trust perspective \\
\hline decision makers. & Interpersonal, Institutional \\
\hline platform operator. & Interpersonal \\
\hline organiser. & Interpersonal \\
\hline tool used. & \\
\hline other participants. & Dispositional, Institutional, Interpersonal \\
\hline democratic structures. & Institutional \\
\hline Internet. & Institutional \\
\hline others generally. & Dispositional, Institutional \\
\hline
\end{tabular}

Trusting beliefs and trusting intentions are related to trustees of type 'specific others'. The element 'trusting intentions' implies some dependence of the trustor towards the trustee and rates the willingness of the trustor for being dependent. In our context, this means that the trustor depends on trustees in regards to the risks listed in section 3.1. However, it would also be possible to express that the trustor is dependent in terms of reaching benefits from these trustees. Some benefits can be expressed as a risk by negation. Yet at the same time, benefits can only be achieved if the participant participates. Some possible benefits can be summarised as: The political situation changes corresponding to participants' interests. The participant took an active role in the decision making process. In Mayer et al.'s model, these benefits cannot be regarded explicitly. Trust-related Behaviours focuses on the participation activity and that the trustor depends on the other stakeholders "with a feeling of relative security, even though negative consequences are possible" (as it is defined in [12, p.34f]).

\subsection{Discussion of the Models' Applicability to e-Participation Contexts}

The Mayer et al. model considers influencing factors before a trustor enters a trust relationship. It also shows how outcomes influence again trustor's perception of trustworthiness to the trustee. Factors of trustworthiness can be applied in interpersonal trust relationships and on intergroup or inter-organisational levels [20] so that trust in individual stakeholders and in groups could be examined. The model clearly differentiates trust from influencing factors and from the relationship that is then 
entered by the trustor. The model shows that, both, the outcomes and the satisfaction with these outcomes influence the assessment of trustworthiness and trustor's further propensity. However, such a feedback to trustor's propensity seems to be missing in this model. Another aspect that is not clearly considered is how a concrete technology or a medium of communication is reflected in the Mayer et al. model.

Assessing the Interdisciplinary Model of Trust Constructs shows some comparable elements with Mayer et al.'s model (propensity to trust, disposition to trust, factors of trustworthiness and trusting beliefs). Beyond that, the McKnight \& Chervany model gives insights into trust in general others, trust in the situation and structures as well as trust in specific others, the links between them and their influence in the decision to participate. These perspectives to trust from psychology, sociology and social psychology are to be considered when analysing trust in e-participation. So both models are complementing each other to some extent.

Other aspects of trust in e-participation are not explicitly reflected in the two models: A clear one to one trustor->trustee relationship (on an interpersonal level) is often not existent in e-participation contexts, as there is not only one relationship responsible for the decision of a trustor to participate. Instead, different relationships with different trustees can influence such a decision. Using different instantiations of Mayer et al.'s model or different perspectives with different instantiations of the interpersonal perspective of McKnight and Chervany's model would make it possible to analyse the interplay. As the investigation of these interplays is perceived as important for e-participation, we make an attempt to combine and extend the two models. Considering 'taking some risk' in order to trust and to decide to enter a 'risk taking relationship' is difficult to rate as valuable in e-participation. It remains unclear whether a participant will be aware of risks and whether they would influence participation. Also risk of non-participation might be the same as for participation in the case that the voice is not heard and the political/legal situation is not changed. Here, the key question would rather be, if benefits of participation should be regarded in addition to risks. Introducing considerations of benefits could help thinking positive, i.e. that the trustor would not depend necessarily in a negative way from the trustee. Hence, the Mayer et al. model (as it rather investigates a trust-risk analysis) could benefit from integrating possible benefits. Both models consider in general trust of one trustor in a trustee so that the person is the "object of trust, rather than the person in one situation" [12, p.34]. In the e-participation context, the specific situation needs to be considered - i.e. the particular participation experience. Hence the trust object could be 'the trustee in regards to some situational context'. Table 2 shows such trust objects, which have been derived after outcomes have been identified along the exemplification of Mayer et al.'s model. These trust objects limit the dependency of the trustor from the trustee. For example, the trustor does not need to trust the government in general but only in proper processing of the participation input. The synthesis shows that both models can provide an appropriate base to analyse trust in e-participation. However, it is also necessary to add e-participation specific elements as already described above. Next section therefore proposes a trust model for e-participation based on the two models studied. 
Table 2. Examples of trust objects in e-participation contexts

\begin{tabular}{|l|l|}
\hline Trust in regards to... & Trustee \\
\hline no manipulation of software (external and internal). & $\begin{array}{l}\text { platform operator/provider (PO), } \\
\text { general public }\end{array}$ \\
\hline no manipulation of hardware (internal). & PO \\
\hline no software and hardware failures. & PO \\
\hline $\begin{array}{l}\text { data are secured in a safe and encrypted environ- } \\
\text { ment. }\end{array}$ & PO \\
\hline $\begin{array}{l}\text { proper processing of trustor's inputs (e.g. no manipu- } \\
\text { lation, processing in compliance with laws and regu- } \\
\text { larities, conform to descriptions). }\end{array}$ & $\begin{array}{l}\text { organiser, responsible political } \\
\text { stakeholders e.g. government }\end{array}$ \\
\hline proper moderating. & organiser (moderator) \\
\hline no personal disadvantages. & government, general public \\
\hline information provided are correct. & PO, information provider \\
\hline proper behaviour of other participants. & $\begin{array}{l}\text { general public } \\
\text { organiser, responsible political } \\
\text { stakeholders e.g. government }\end{array}$ \\
\hline transparency is provided. & \multicolumn{2}{|l}{} \\
\hline
\end{tabular}

\section{A Trust Model for e-Participation}

The proposed trust model for e-participation as presented in Fig. 4 combines the Integrative Model for Trust in Organisational Settings and the Interdisciplinary Model of Trust Constructs. The Mayer et al. model brings in the dynamic relationships in trust and e-participation, i.e. the relationship between trustor and trustee, trust-related behaviour, which results in outcomes, and the assessment of outcomes influencing factors of perceived trustworthiness. The McKnight and Chervany model adds considerations of trust in others, the situation or structures, and the respective relationships. From the lessons of exemplifying the trust models in e-participation contexts, we add the perceived benefit of a participation action. We rename the RTR in participation as the action since we embark on a positivist approach.

Trustor's Propensity to Trust / Disposition to Trust as characteristics of the trustor describes that ,some parties are more likely to trust than are others" [11, p.714]. It indicates the "general willingness to trust others" [11, p.715] that is further modelled with sub-elements 'faith in humanity' and 'trusting stance' [12, p.38f].

Trustor's Trust in Situation, Structures is based on the concept of 'institutionbased trust' [12] with two sub-elements: (i) 'Structural assurance describing that the trustor "securely believes that protective structures - guarantees, contracts, regulations, promises, legal recourse, processes, or procedures - are in place that are conducive to situational success" [12, p.37]. In Fig. 4 some forms of trust with relevance for e-participation are listed in this element. McKnight \& Chervany exemplify it as "Using the Internet would have structural assurance to the extent that one believed legal and technological safeguards (e.g. encryption) protect one from privacy loss or credit card fraud" [12, p.37]. Blind sees trust in the Internet (see also [27]) as one form of technological trust [8]. 


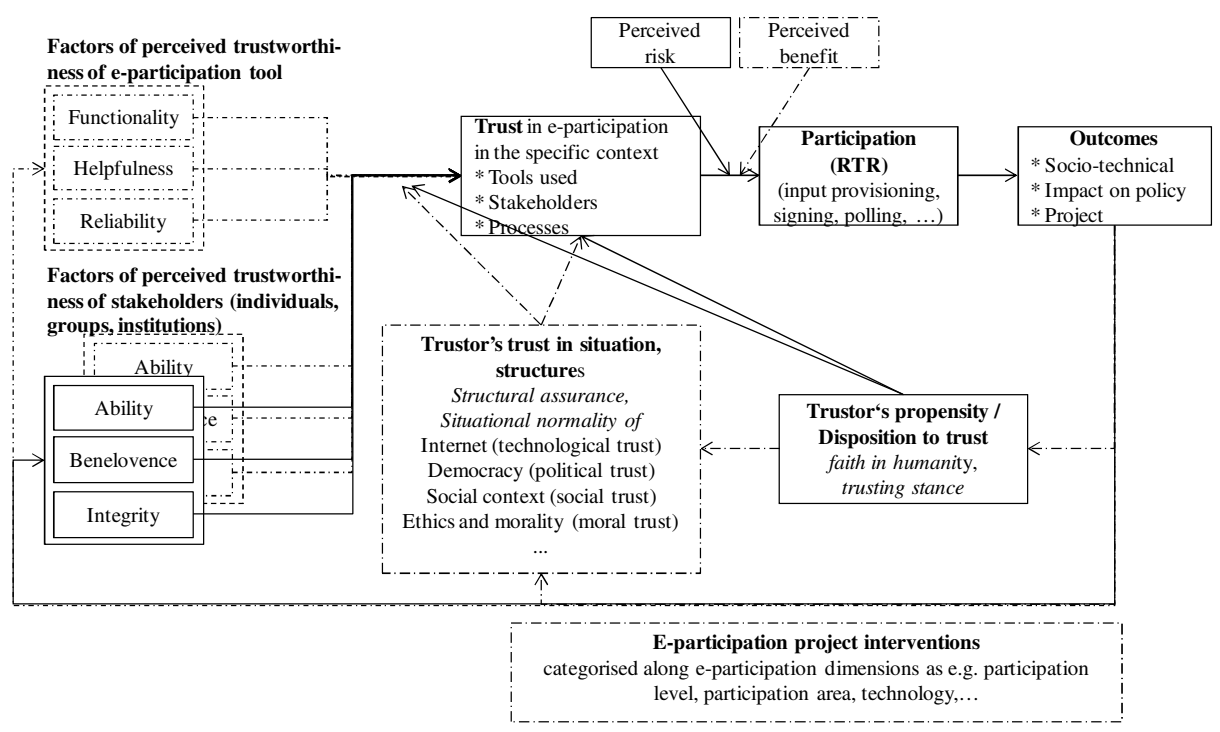

Fig. 4. Trust model for e-participation contexts combining the elements of the integrative model for trust in organisational settings [11] (solid lines and boxes) and the interdisciplinary model of trust [12] and insights for e-participation (dotted lines and boxes)

Factors of perceived trustworthiness of stakeholders (individuals, groups, institutions) as an attribute of the trustees aims to provide a means for understanding "why a given party will have a greater or lesser amount of trust for another party" [11, p.716]. Participation means to take part and to be engaged in a process or act [7, p.402] (individual level). Yet, it may concern also a membership in a group or community [28, p.14] that usually involves a sense of solidarity (institutional/organisa-tional level). The model proposed indirectly deals with this aspect as groups and organisations involved are evaluated for their trustworthiness in this element, which influences trust of participant. Trustworthiness is seen as 'a continuum'. So the trustee cannot be seen as "either trustworthy or not" [11, p.721]. Mayer et al. propose ability, benevolence, and integrity as the factors of trustworthiness [11, p.717ff]. The three factors are 'separable' but not unrelated [11, p.720].

Factors of perceived trustworthiness of e-participation tool include electronic and procedural components to the model. In order to consider technology, Plankton and McKnight propose to parallelise "the three technology-related trust beliefs" with "the three most commonly used interpersonal trust beliefs" [29, p.33]. The authors suggest the following analogies: functionality = ability, reliability = integrity, helpfulness $=$ benevolence $[29$, p.33].

Trustor's trust in e-participation in the specific context considers all involved stakeholders that might be individual persons (as e.g. politicians) or organisations (as e.g. the particular government). This concept also considers trust in particular tools and processes used in the specific e-participation context. Trust in e-participation is a function of (1) "the trustee[s]' perceived ability, benevolence, and integrity" 
[11, p.720], (2) “the trustor's propensity to trust” [11, p.720], (3) trustor's trust in situation and structures, and (4) tools and processes perceived as functional, helpful and reliable.

Perceived risk "involves the trustor's belief about likelihoods of gains or losses outside of considerations that involve the relationship with the particular trustee" [11, p.726]. We add Perceived benefit as influencing factor for entering the participation relationship that involves the trustor's belief about advantages and positive outcomes.

Participation describes the action that is taken by the trustor as result of trust. Specifics for e-participation, which need to be included, are e-participation activities. Mayer et al. propose the following function comparing the level of trust to the level of perceived risk in a situation: "If the level of trust surpasses the threshold of perceived risk, then the trustor will engage in the RTR. If the level of perceived risk is greater than the level of trust, the trustor will not engage in the RTR" [11, p.726].

Outcomes is conforming to the corresponding concept in Mayer et al.'s model [11, p.728]: Positive outcomes enhance trustor's propensity to trust in others, in the situation and structures, and in specific others. Likewise, perceptions "will decline when trust leads to unfavourable conclusions" [11, p.728]. The outcome of trusting behaviour can influence different trust elements; in which form is still subject of research. For the analysis, the evaluation framework by Macintosh and Whyte is proposed, which proposes socio-technical, project and democratic criteria for evaluating outcomes [30, p.21ff].

E-Participation project interventions regard possible e-participation project characteristics that can influence trust. The aim of this element is to provide the possibility to investigate different design decisions in an e-participation project in regards to effects on trust (derived from "Web Vendor Interventions" in [14, p.44]). A starting point for sub-elements can be Macintosh's e-participation key dimensions that are aiming to "capture any political, legal, cultural, economic, or technological factor that stands out so as to make the e-participation a success" [31, p.6].

\section{$5 \quad$ Concluding Remarks}

This paper has investigated trust in e-participation contexts. The main aim was to conceptualise an understanding of trust in e-participation contexts. The literature review evaluated models for trust in regards to their applicability to e-participation. Two models have been selected for further examination as these are often cited in literature: a) the Integrative Model of $\mathrm{O}$ organisational Trust and the $\mathrm{b}$ ) Interdisciplinary Model of Trust Constructs. To meet the needs of understanding trust in e-participation contexts, the two models have been combined to 1) investigate trust along the whole lifecycle of e-participation projects with a) and to 2) consider different trust perspectives (general, system, individual) with b). Some model elements have been revised and amended to better suit the e-participation context.

Further research is needed to evaluate the proposed trust model for e-participation contexts and the suggested elements and linkages between them through empirical research and through examination against existing theories in other disciplines as e.g. psychology. In a next step, we will define relevant research questions and categorise 
them using the elements of the trust model conceptualised for e-participation. As the model is currently only reflecting the participant as trustor, further research will investigate the viewpoints of other roles as e.g. trust of administrative agencies e. g. in the input of the general public necessary for starting an e-participation initiative. Overall, this research is also to be complemented with investigations studying distrust in e-participation and whether the distrust aspect will lead to further revisions of the trust model for e-participation contexts. It needs to be investigated how far people's motivation to participate influences trust and the decision to participate, and if relevant elements should be integrated in the model.

Acknowledgement. This work was partially funded by the KoMePol project, a Research Initiative (Stage II) of the State Rhineland-Palatinate, Germany. The authors acknowledge the contributions of and express their gratitude to KoMePol project partners for the discussions of the Trust model for e-participation, especially to Rüdiger Grimm.

\section{References}

1. Coleman, S., Götze, J.: Bowling Together: Online Public Engagement in Policy Deliberation. Hansard Society (2002)

2. Grimmelikhuijsen, S.G., Meijer, A.J.: Effects of Transparency on the Perceived Trustworthiness of a Government $\mathrm{O}$ organisation: Evidence from an Online Experiment. Journal of Public Administration Research and Theory 24, 137-157 (2014)

3. Im, T., Cho, W., Porumbescu, G., Park, J.: Internet, Trust in Government, and Citizen Compliance. Journal of Public Administration Research and Theory (2012)

4. Kim, S., Lee, J.: E-participation, transparency, and trust in local government. Public Administration Review 72, 819-828 (2012)

5. Seligson, M.A.: Trust, efficacy and modes of political participation: a study of Costa Rican peasants. British Journal of Political Science 10, 75-98 (1980)

6. Uslaner, E.M., Brown, M.: Inequality, trust, and civic engagement. American Politics Research 33, 868-894 (2005)

7. Saebo, O., Rose, J., Flak, L.S.: The shape of eParticipation: characterizing an emerging research area. Government Information Quarterly 25, 400-428 (2008)

8. Blind, P.K.: Building Trust in Government in the Twenty-First Century: Review of Literature and Emerging Issues. In: 7th Global Forum on Reinventing Government Building Trust in Government, pp. 26-29 (2006)

9. Luhmann, N.: Vertrautheit, Zuversicht, Vertrauen: Probleme und Alternativen. In: Hartmann, M., Offe, C. (eds.) Vertrauen-Die Grundlage des sozialen Zusammenhalts, pp. 143-160. Campus Verlag, Frankfurt (2001)

10. Luhmann, N.: Vertrauen: Ein Mechanismus der Reduktion sozialer Komplexität. Ferdinand Enke Verlag, Stuttgart (1973)

11. Mayer, R.C., Davis, J.H., Schoorman, F.D.: An Integrative Model of O organisational Trust. The Academy of Management Review 20, 709-734 (1995)

12. McKnight, D.H., Chervany, N.L.: Trust and Distrust Definitions: One Bite at a Time. In: Falcone, R., Singh, M., Tan, Y.-H. (eds.) AA-WS 2000. LNCS (LNAI), vol. 2246, pp. 27-54. Springer, Heidelberg (2001)

13. Lewis, J.D., Weigert, A.: Trust as a Social Reality. Social Forces 63, 967-985 (1985) 
14. McKnight, D.H., Chervany, N.L.: What Trust Means in E-Commerce Customer Relationships: An Interdisciplinary Conceptual Typology. International Journal of Electronic Commerce 6, 35-59 (2001)

15. Bannister, F., Connolly, R.: Trust and transformational government: A proposed framework for research. Government Information Quarterly 28, 137-147 (2011)

16. Hartmann, M.: Die Praxis des Vertrauens. Surkamp Verlag, Berlin (1994)

17. Petermann, F.: Psychologie des Vertrauens. Hogrefe-Verlag, Göttingen (1996)

18. Seligman, A.B.: The problem of trust. Princeton University Press, Boulder (1997)

19. Papadopoulou, P., Nikolaidou, M., Martakos, D.: What is trust in e-government? a proposed typology. In: 2010 43rd Hawaii International Conference on System Sciences (HICSS), pp. 1-10. IEEE (2010)

20. Schoorman, F.D., Mayer, R.C., Davis, J.H.: Editor's forum - An integrative model of organisational trust: past, present and future. Academy of Management Review 32, 344-354 (2007)

21. Knight, D.H.M., Chervany, N.L.: Reflections on an initial trust-building model. Handbook of trust research, p. 29. Edward Elgar Publishing (2006)

22. McKnight, D.H., Cummings, L.L., Chervany, N.L.: Initial trust formation in new organisational relationships. Academy of Management Review 23, 473-490 (1998)

23. Akkaya, C., Obermeier, M., Wolf, P., Krcmar, H.: Components of Trust Influencing eGovernment Adoption in Germany. In: Janssen, M., Scholl, H.J., Wimmer, M.A., Tan, Y.-h. (eds.) EGOV 2011. LNCS, vol. 6846, pp. 88-99. Springer, Heidelberg (2011)

24. Wang, X., Wan Wart, M.: When public participation in administration leads to trust: An empirical assessment of managers' perceptions. Public Administration Review 67, 265-278 (2007)

25. Veit, D., Parasie, N., Schoppé, F.: Bürgernahes Regieren: Lässt sich politische Beteiligung durch E-Participation Anwendungen verbessern? In: Schumann, M., Kolbe, L.M., Breitner, M.H., Frerichs, A. (eds.) Multikonferenz Wirtschaftsinformatik 2010, Universitätsverlag Göttingen, pp. 1343-1355 (2010)

26. Lee, J., Kim, S.: Active Citizen E-Participation in Local Governance: Do Individual Social Capital and E-Participation Management Matter? In: Hawaii International Conference on System Sciences (HICSS-47) (2014)

27. Dutton, W.H., Shepherd, A.: Trust in the Internet: The Social Dynamics of an Experience Technology. Oxford Internet Institute University of Oxford (2003)

28. Albrecht, S., Kohlrausch, N., Kubicek, H., Lippa, B., Märker, O., Trénel, M., Vorwerk, V., Westholm, H., Wiedwald, C.: eParticipation - electronic participation of citizens and the business community in eGovernment. Study on Behalf of the Federal Ministry of the Interior (Germany) conducted by IFIB Bremen GmbH and Zebralog GmbH (2008)

29. Lankton, N.K., McKnight, D.H.: What Does it Mean to Trust Facebook? Examining Technology and Interpersonal Trust Beliefs. The DATA BASE for Advances in Information Systems 42, 32-54 (2011)

30. Macintosh, A., Whyte, A.: Towards an evaluation framework for eParticipation. Transforming Government: People, Process and Policy 2, 16-30 (2008)

31. Macintosh, A.: Characterizing e-participation in policy-making. In: Proceedings of the 37th Annual Hawaii International Conference on System Sciences, pp. 10-19. IEEE Computer Society, Los Alamitos (2004) 